\title{
Riscos biomecânicos e ocupacionais em uma central de materiais e esterilização
}

\author{
Biomechanical and occupational risks in a \\ material and sterilization central
}

\author{
Jihad Ali Ibrahim Iskandar ${ }^{1}$ (1) \\ Ana Luiza Pedrini Muzeka ${ }^{2}$ (1) \\ Cecília Motter Haus 3 [D
}

Felipe Afonso Ramos Pereira de $\mathrm{Melo}^{4}$ (1)

Arlete Ana Motter 5 (1)

19utor para correspondência. Universidade Federal do Paraná (Curitiba). Paraná, Brasil. jihadiskandar1@gmail.com
2,5Universidade Federal do Paraná (Curitiba). Paraná, Brasil. alpmuzeka@gmail.com, arlete.motter@uol.com.br
3,4Colégio Marista Paranaense (Curitiba). Paraná, Brasil.ceci.m.haus@gmail.com, felipe_melo2004@hotmail.com

RESUMO | INTRODUÇÃO: Os profissionais que atuam na central de material e esterilização (CME) possuem a função de recepcionar, limpar, esterilizar, embalar e armazenar utensílios utilizados em cirurgias no hospital. Trata-se, assim, de uma profissão de grande exigência física e mental, com alta carga de trabalho e estresse. OBJETIVO: Analisar os riscos biomecânicos e os sintomas osteomioarticulares de servidores da CME de um complexo hospitalar público. MATERIAIS E MÉTODOS: Estudo observacional prospectivo que foi desenvolvido em um hospital público do sul do país. Participaram 20 profissionais, tais como auxiliares, técnicos e enfermeiros. Os critérios de inclusão foram que o indivíduo atuasse na CME, ser auxiliar, técnico ou enfermeiro da CME ao menos há 6 meses, idade igual ou maior que 18 anos, de ambos os sexos, e exercer qualquer função. Os critérios de exclusão foram estar em período de férias ou licença saúde/capacitação no período de coleta de dados, trabalhar no setor há menos de 6 meses. Instrumentos de coleta: questionário sociodemográfico internacional de atividade física (IPAQ) - versão curta e o Nórdico de Sintomas Osteomusculares. RESULTADOS: Verificou-se que $85 \%$ dos profissionais são do sexo feminino; a idade média foi de 47 anos; $70 \%$ são auxiliares de enfermagem; 85\% dos profissionais possuem filhos; $35 \%$ apresentaram dores em pescoço, punhos/mãos e quadril/coxas; $85 \%$ sentem dores de cabeça recorrentes; $50 \%$ já sofreram algum acidente de trabalho, sendo $80 \%$ com perfurocortantes. CONCLUSÃo: Conclui-se que os servidores de CME têm riscos biomecânicos e ocupacionais. Assim, medidas preventivas devem ser adotadas para minimizar riscos à saúde física e mental dos mesmos.

PALAVRAS-CHAVE: Distúrbio osteomuscular relacionado ao trabalho. Saúde do trabalhador. Enfermagem.
ABSTRACT | INTRODUCTION: Professionals working in the Material and Sterilization Central (MSC) have the function of receiving, cleaning, sterilizing, packing, and storing utensils used in hospital surgeries. It is thus a profession of great physical and mental demand with high workload and stress. OBJECTIVE: To investigate the biomechanical and osteomioarticular symptoms of employees of a CME in a hospital complex. METHODS: It is characterized as observational and prospective, developed in a public hospital in the south of the country. Twenty professionals participated, such as assistants, technicians, and nurses, who answered the sociodemographic, international physical activity questionnaires (IPAQ) - short and Nordic Musculoskeletal Symptoms. RESULTS: It was found that $85 \%$ of professionals are female; the mean age was 47 years; $70 \%$ are nursing assistants; $85 \%$ of the professionals have children; $35 \%$ had neck pain, wrists/hands, and hip/thighs; $85 \%$ experience recurrent headaches; $50 \%$ have already suffered some work accident, $80 \%$ with sharps. CONCLUSION: It is concluded that MSC servers have biomechanical and occupational risks and that preventive measures should minimize risks to their physical and mental health.

KEYWORDS: Cumulative Trauma Disorders. Occupational Health. Nursing. 


\section{Introdução}

Qualquer dano que eventualmente um trabalhador venha a ter no exercício de sua atividade laboral é considerado um risco ocupacional, ou seja, são acidentes ou doenças possíveis a que estão expostos os trabalhadores na rotina de trabalho ou por motivo da ocupação que exercem. Já o risco biomecânico relaciona-se à maneira como um trabalhador é afetado pelas forças, posturas e movimentos inerentes às atividades de trabalho que realiza. ${ }^{1}$

A esterilização de objetos, roupas, equipamentos e materiais utilizados em uma cirurgia é de grande importância, pois só através desse processo é que os microrganismos são destruídos, o que evita a contaminação e a transmissão de doenças entre os pacientes.? Este processo visa incapacitar a reprodução de todos os microrganismos presentes nos materiais. Desse modo, há um setor do hospital responsável pela esterilização dos materiais considerados sujos ou contaminados: a Central de Material e Esterilização (CME). Além disso, esta central também é responsável pelo preparo, pelo armazenamento e pela distribuição dos materiais para as demais áreas do hospital. Os trabaIhadores que atuam neste setor são enfermeiros, técnicos de enfermagem e auxiliares de enfermagem. ${ }^{3}$

Estes profissionais estão expostos diariamente aos riscos de contaminação com agentes físicos (ruídos, vibrações, radiações ionizantes, frio, calor, umidade), químicos ( poeira, fumo, nevoas, gases, vapor) e biológicos ( vírus, bactérias, protozoários, fungos, parasitas e bacilos), o que torna a CME um local de trabalho no hospital totalmente diferente dos demais. ${ }^{4}$ Além disso, aliam-se aos riscos psicossociais que a profissão apresenta, que engloba as relações conflituosas ou não entre os profissionais, os ritmos intensos, a alta demanda e o trabalho em turnos. .5 Os riscos ergonômicos também estão presentes na CME e podem estar relacionados a diversos fatores, como o mobiliário, as ferramentas de trabalho e a logística, assim como as condições de trabalho, seja no transporte, levantamento ou descarga de materiais.

Os riscos biológicos se apresentam por meio de microrganismos que podem gerar diversas doenças, quando entram em contato com o ser humano. Esses riscos, quando aliados, podem gerar acidentes. Sendo assim, a CME é dividida em cinco áreas e possui etapas complexas que tem como dever garantir materiais livres de qualquer contaminação para diversos procedimentos cirúrgicos. As cinco áreas são: área de recepção e limpeza (setor sujo); área de preparo e esterilização (setor limpo); área de desinfecção química, quando aplicável (setor limpo); área de monitoramento do processo de esterilização (setor limpo); área de armazenamento e distribuição de materiais esterilizados (setor limpo). ${ }^{4}$

Com isso, o procedimento de limpeza começa com a inspeção do material, o que garante a segurança do trabalhador, assim como a inspeção do estado dos artigos e a desmontagem do material, quando necessária. Em seguida, é realizada a etapa mais importante do processo: a limpeza. Nesta etapa, é reduzido a quantidade de biofilme, de microrganismos e das substâncias pirogênicas. A próxima parte do processo é o preparo dos materiais, que envolve a secagem e a organização dos utensílios, que resulta nos objetos embalados e prontos para a esterilização. Em seguida, os artigos são esterilizados com vapor saturado sob pressão e com peróxido de hidrogênio. Por fim, as bandejas contendo os materiais esterilizados são armazenados para posteriormente serem usados novamente em procedimentos cirúrgicos. $\frac{6}{}$

Porém, o grande número de cirurgias realizadas diariamente gera muito material contaminado, o que resulta em uma carga expressiva de trabalho para as centrais e que acaba, muitas vezes, sobrecarregando os profissionais que atuam neste processo. ${ }^{3.5}$ Essa sobrecarga gera o estresse relacionado ao trabalho, potencializando os riscos físicos, biológicos, químicos e ergonômicos a que os trabalhadores estão expostos diariamente. ${ }^{4, Z}$ Nessas condições, os acidentes de trabalho se tornam mais comuns de acontecerem. Já as disfunções musculoesqueléticas, tais como as LER/DORT (Lesão por esforço repetitivo/Distúrbio Osteomuscular relacionado ao Trabalho), também estão presentes entre os funcionários de uma central de material e esterilização, visto que os movimentos realizados são altamente repetitivos e lesivos, além de serem aliados a uma grande intensidade de trabalho.., 9

Para resguardar os direitos de segurança no trabalho em serviços de saúde, a Norma Regulamentadora $\mathrm{n}^{\circ}$ 32 (NR-32) foi criada em 2005 e foi considerada uma grande conquista dos profissionais envolvidos na área da saúde, pois garante uma maior proteção à saúde do trabalhador. Com a NR-32, é necessária uma adequação às normas, o que gera um investimento 
na infraestrutura, no número de funcionários e em materiais, como os equipamentos de proteção individual para o trabalhador..$^{10} \mathrm{O}$ presente estudo tem por objetivo analisar os riscos biomecânicos e os sintomas osteomioarticulares de servidores que atuam em uma central de material e esterilização de um hospital brasileiro da região sul do país.

\section{Metodologia}

O estudo foi do tipo observacional, prospectivo, cuja coleta de dados ocorreu durante três meses no complexo hospitalar de uma universidade pública do sul do país, mas teve de ser interrompida devido à pandemia por COVID 19, em março de 2020. Foi aprovado previamente pelo Comitê de ética em Pesquisa com seres humanos da própria instituição sob o parecer de 02/05/2019 (CAAE 45968715.6.3002.0096).

Uma vez autorizado, foram realizadas três visitas de observação para conhecer o contexto e a organização do trabalho na CME. Depois disso, a coleta de dados ocorreu nos próprios postos de trabalho, com a participação voluntária dos servidores/funcionários do local. O recrutamento dependia da disponibilidade dos profissionais que estavam presentes, que eram entrevistados em um momento de pausa do trabalho, ou até mesmo enquanto realizavam atividades em que fosse permitido o diálogo com os pesquisadores, simultaneamente. A aplicação dos questionários durou entre 15 e 30 minutos e foi realizada de maneira individual, a fim de manter o sigilo das informações. Utilizou-se três instrumentos para a coleta de dados, sendo eles: a) o Questionário sociodemográfico; b) o Questionário Internacional de Atividade Física (IPAQ) - versão curta; c) o Questionário Nórdico.

\section{Critérios de inclusão e exclusão}

Os critérios de inclusão foram que o indivíduo atuasse na CME, ser auxiliar, técnico ou enfermeiro da CME ao menos há 6 meses, idade igual ou maior que 18 anos, de ambos os sexos e exercer qualquer função. Já os critérios de exclusão foram estar em período de férias ou licença saúde/capacitação no período de coleta de dados, trabalhar no setor há menos de 6 meses.

A Figura 1 ilustra a seleção, inclusão ou exclusão dos participantes. A princípio, foram identificados 58 possíveis participantes; contudo, 33 participantes foram excluídos por se encontrarem em período de férias ou em período de licença por motivos de saúde ou capacitação durante o período de coleta de dados. Dos 25 restantes, 2 foram excluídos por trabalharem há menos de 6 meses na unidade e outros 3 por recusarem-se a participar do estudo.

Figura 1. Etapas seguidas no estudo para seleção e inclusão/exclusão dos participantes

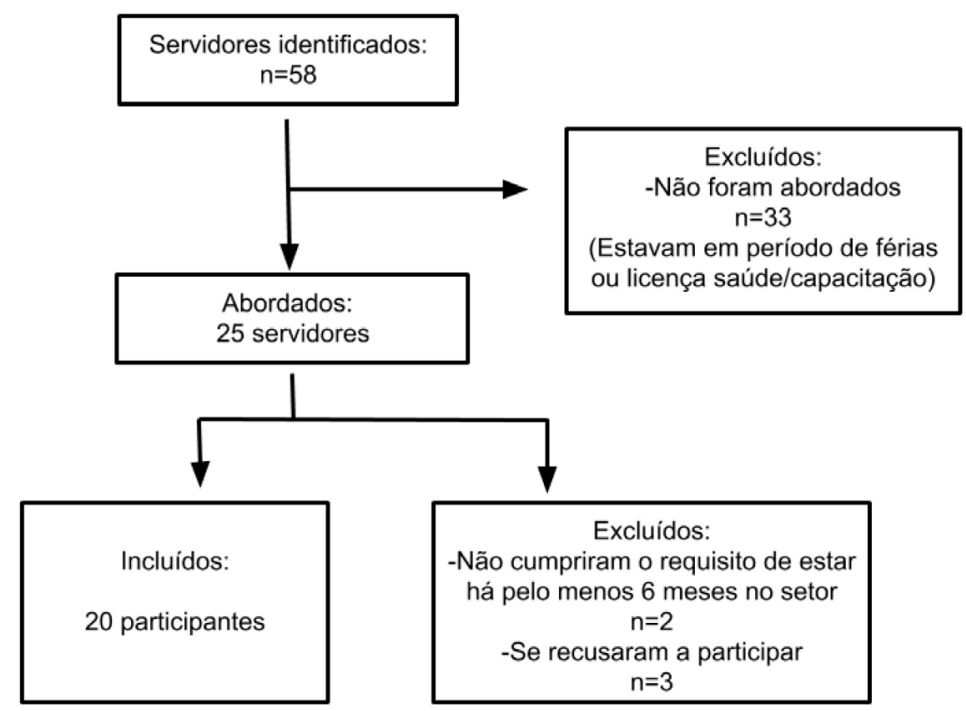




\section{Instrumentos de coleta}

\section{Questionário sociodemográfico}

Para obter os dados desta pesquisa, foi utilizado o questionário sociodemográfico elaborado pelos próprios pesquisadores, com o objetivo de obter os dados pessoais e mapear um perfil da população que participou. O questionário contém 48 questões, sendo 26 sobre dados pessoais, 4 sobre a avaliação da dor, 6 sobre acidentes de trabalho, 2 sobre saúde e trabalho, 6 sobre o reconhecimento e satisfação no trabalho e 4 sobre a percepção de riscos ocupacionais. As medidas de peso e estatura para cálculo do Índice de Massa Corpórea (IMC) foram obtidas através das informações dos próprios participantes. Calculou-se o IMC da seguinte forma: dividiu-se o peso do paciente pela sua altura elevada ao quadrado. Diz-se que o indivíduo tem peso normal quando o resultado do IMC está entre 18,5 e 24,9.11

\section{Questionário Internacional de atividade física (IPAQ) - versão curta}

O IPAQ - versão curta foi utilizado para se obter informações sobre o quão ativa fisicamente era a vida do participante. Este questionário é composto por 8 questões, e sugere aproximadamente o tempo em que o indivíduo realiza caminhadas, atividades moderadas e vigorosas, e obtém o tempo em que o entrevistado permanece sentado em um dia comum e em um dia de final de semana. ${ }^{12}$

\section{Questionário Nórdico de Sintomas Osteomusculares}

O questionário utilizado para avaliar a dor foi o Nórdico, em que especifica cada local do corpo em um mapa visual, separando em região cervical, ombros, região dorsal, cotovelos, punhos/mãos, região lombar, quadril/coxas, joelhos e tornozelos/pés, possuindo perguntas acerca da região indicada. $O$ instrumento foi validado por Pinheiro et al. ${ }^{13}$ As respostas são "sim" ou "não", e mapeiam a dor do entrevistado, incluindo até a necessidade em procurar por uma ajuda médica e restrições de atividades diárias.

\section{Análise estatística}

A partir dos dados obtidos, foi realizada análise descritiva, sendo utilizadas as frequências absolutas e porcentagens para dados qualitativos, e média e desvio padrão para dados quantitativos. As análises foram feitas no software Microsoft Excel 2016.

\section{Resultados}

Participaram 20 servidores/funcionários da equipe da $\mathrm{CME}$, distribuídos em 14 técnicos em enfermagem, 3 auxiliares em enfermagem e 3 enfermeiros. A Tabela 1 apresenta os dados em relação à identificação dos participantes, como a profissão, o sexo, a idade, o estado civil, a escolaridade, o tempo na ocupação, a carga de trabalho e o vínculo empregatício. 
Tabela 1. Análise descritiva do questionário aplicado a servidores da central de material e esterilização, no ano 2020

\begin{tabular}{|c|c|c|}
\hline Variável & Categoria & $N(\%)$ \\
\hline \multirow[t]{2}{*}{ Gênero } & Feminino & $17(85 \%)$ \\
\hline & Masculino & $3(15 \%)$ \\
\hline \multicolumn{2}{|l|}{ Idade média } & $47,7( \pm 8,53)^{*}$ \\
\hline \multicolumn{2}{|l|}{ IMC } & $26,9( \pm 5,42)^{*}$ \\
\hline \multicolumn{3}{|l|}{ Estado civil } \\
\hline & Solteiro & $4(20 \%)$ \\
\hline & Casado ou união estável & $12(60 \%)$ \\
\hline & Divorciado & $12(60 \%)$ \\
\hline \multicolumn{3}{|l|}{ Escolaridade } \\
\hline & Ensino médio ( $2^{\circ} \mathrm{grau}$ ) completo & $13(65 \%)$ \\
\hline & Ensino superior incompleto & $4(20 \%)$ \\
\hline & Ensino superior completo & $1(5 \%)$ \\
\hline & Pós-graduação & $2(10 \%)$ \\
\hline \multirow[t]{2}{*}{ Possui filhos } & $\operatorname{Sim}$ & $17(85 \%)$ \\
\hline & Não & $3(15 \%)$ \\
\hline \multicolumn{3}{|l|}{ Atuação } \\
\hline & Técnico de enfermagem & $14(70 \%)$ \\
\hline & Auxiliar de enfermagem & $3(15 \%)$ \\
\hline & Enfermeiro & $3(15 \%)$ \\
\hline \multicolumn{3}{|c|}{ Tempo na ocupação } \\
\hline & 6 meses a 2 anos & $8(40 \%)$ \\
\hline & 2 a 5 anos & $6(30 \%)$ \\
\hline & 7 a 10 anos & $3(15 \%)$ \\
\hline & Mais de 10 anos & $3(15 \%)$ \\
\hline \multicolumn{3}{|c|}{ Turno de trabalho } \\
\hline & Manhã & $10(50 \%)$ \\
\hline & Tarde & $8(40 \%)$ \\
\hline & Noite & $2(10 \%)$ \\
\hline \multicolumn{3}{|c|}{ Carga horária semanal } \\
\hline & 30 horas & $3(15 \%)$ \\
\hline & 36 horas & $14(70 \%)$ \\
\hline & 40 horas & $3(15 \%)$ \\
\hline \multicolumn{3}{|c|}{ Vínculo empregatício } \\
\hline & EBSERH & $13(65 \%)$ \\
\hline & FUNPAR & $5(25 \%)$ \\
\hline & Reitoria & $2(10 \%)$ \\
\hline
\end{tabular}

* Valores da média \pm desvio padrão 
A Tabela 1 expõe que os participantes são, em sua maioria, técnicos de enfermagem (70\%), do sexo feminino (85\%), casados (60\%), com a idade média de 47 anos, escolaridade até o $2^{\circ}$ grau completo (65\%), possuem filhos (85\%), de 6 meses a 2 anos na ocupação (40\%), com turno de trabalho de manhã (50\%), possuindo a carga horária semanal de 36 horas (70\%) e vínculo empregatício EBSERH (65\%).

A Tabela 2 apresenta dados sobre hábitos cotidianos, acidentes de trabalho e problemas de saúde dos participantes da pesquisa.

Tabela 2. Análise descritiva dos hábitos de vida, acidentes de trabalho e problemas de saúde dos servidores de um CME no ano de 2020

\begin{tabular}{|c|c|c|}
\hline Questão & Categorias & $N(\%)$ \\
\hline \multirow[t]{2}{*}{ Faz uso de cigarro } & Sim & $3(15 \%)$ \\
\hline & Não & $17(85 \%)$ \\
\hline \multirow[t]{2}{*}{ Ingere bebidas alcoólicas } & $\operatorname{Sim}$ & $5(25 \%)$ \\
\hline & Não & $15(75 \%)$ \\
\hline \multirow[t]{2}{*}{ Faz uso de medicamentos } & Sim & $9(45 \%)$ \\
\hline & Não & $11(55 \%)$ \\
\hline \multirow[t]{2}{*}{ Realiza atividades domésticas após expediente } & $\operatorname{Sim}$ & $19(95 \%)$ \\
\hline & Não & $1(5 \%)$ \\
\hline \multirow[t]{2}{*}{ Já sofreram algum acidente de trabalho } & Sim & $10(50 \%)$ \\
\hline & Não & $10(50 \%)$ \\
\hline \multicolumn{3}{|l|}{ Qual foi o acidente de trabalho } \\
\hline & Com perfurocortante & $8(80 \%)$ \\
\hline & Com descarga de peso & $1(10 \%)$ \\
\hline & Com altas temperaturas & $1(10 \%)$ \\
\hline \multicolumn{3}{|l|}{ Qual o principal motivo que causou o acidente } \\
\hline & Condições de segurança insuficientes ou inadequadas & $4(40 \%)$ \\
\hline & Falha técnica & $4(40 \%)$ \\
\hline & Estresse & $1(10 \%)$ \\
\hline & Pressão em relação à prazos & $1(10 \%)$ \\
\hline \multicolumn{3}{|l|}{ Manifestação de sintomas recentes* } \\
\hline & Dores de cabeça & $17(85 \%)$ \\
\hline & Dores no peito & $7(35 \%)$ \\
\hline & Dores na coluna & $10(50 \%)$ \\
\hline & Dores no estômago & $7(35 \%)$ \\
\hline & Indigestão, vômito, diarreia & $5(25 \%)$ \\
\hline & Adormecimento/formigamento de braços ou pernas & $8(40 \%)$ \\
\hline & Desânimo, fadiga muscular & $9(45 \%)$ \\
\hline & Ansiedade ou irritabilidade & $15(75 \%)$ \\
\hline & Problemas de pele & $7(35 \%)$ \\
\hline & Problemas de visão & $12(60 \%)$ \\
\hline & Problemas de audição & $5(25 \%)$ \\
\hline & Problemas de voz & $4(20 \%)$ \\
\hline & Problemas de sono & $9(45 \%)$ \\
\hline & Problemas relacionados a fungos, vírus ou bactérias & $4(20 \%)$ \\
\hline & Acredita que estes sintomas estão relacionados ao trabalho & $16(80 \%)$ \\
\hline
\end{tabular}

* Categoria com múltiplas escolhas 
A maioria dos entrevistados não considera as condições de trabalho satisfatórias $(n=16)$ e concordam que a cobrança de produção interfere na qualidade do seu trabalho. Entretanto, 70\% gostaria que seus filhos realizassem o mesmo trabalho que o seu, caso manifestassem interesse. Além disso, 75\% dos participantes acham que a sociedade não valoriza o seu trabalho, e $55 \%$ afirmam que os usuários não demonstram satisfação ou gratidão com o seu trabalho. Em relação à remuneração, $65 \%$ consideram que é compatível com as suas atribuições e responsabilidades.

Ademais, 45\% dos servidores consideram os perfurocortantes o maior risco da sua profissão, o que corrobora com os dados apresentados na Tabela 2, onde o maior índice de acidentes foi com esse tipo de material. 0 risco de contaminação vem em segundo lugar, seguido dos riscos ergonômicos. Em relação aos EPI's, pelo menos 75\% dos usuários utilizam luvas de procedimento, óculos e gorros, enquanto apenas $20 \%$ utilizam o protetor auricular. O avental é utilizado por todos os participantes.

Dos 20 servidores entrevistados, a maioria foi classificada como ativa (70\%), seguido por 4 sedentários, 1 insuficientemente ativo e 1 muito ativo, baseado no Questionário Internacional de atividade física (IPAQ) - versão curta.

Os resultados alcançados com o Questionário Nórdico encontram-se na Figura 2.

Figura 2. Resultados do Questionários Nórdico dos participantes, 2020

\begin{tabular}{|c|c|c|c|c|}
\hline I & $\begin{array}{c}\text { Nos últimos } \\
12 \text { meses teve } \\
\text { problema em: }\end{array}$ & $\begin{array}{c}\text { Foi impedido de } \\
\text { realizar } \\
\text { atividades } \\
\text { normais }\end{array}$ & $\begin{array}{c}\text { Consultou } \\
\text { profissional da } \\
\text { saúde }\end{array}$ & $\begin{array}{c}\text { Nos últimos 7 } \\
\text { dias teve } \\
\text { problema em: }\end{array}$ \\
\hline Pescoço & 7 & 4 & 5 & 3 \\
\hline Ombro & 6 & 3 & 4 & 3 \\
\hline $\begin{array}{c}\text { Parte superior das } \\
\text { costas }\end{array}$ & 6 & 2 & 2 & 3 \\
\hline Cotovelo & 3 & 2 & 2 & 4 \\
\hline Punhos/mãos & 7 & 3 & 4 & 4 \\
\hline $\begin{array}{c}\text { Parte inferior das } \\
\text { costas }\end{array}$ & 6 & 2 & 3 & 3 \\
\hline Quadrillcoxas & 7 & 2 & 3 & 4 \\
\hline Joelhos & 5 & 2 & 3 & 4 \\
\hline Tornozelos/pés & 4 & 2 & 2 & 3 \\
\hline
\end{tabular}

A Figura 2 expõe os dados obtidos através do questionário nórdico de sintomas osteomusculares e aponta as dores nos punhos/mãos, no pescoço e no quadril/ coxas como os maiores problemas dos servidores, representando 35\% dos entrevistados. Além disso, o pescoço foi o maior motivo de consultas a um profissional de saúde e responsável pelo maior número de afastamentos temporários das atividades normais. 


\section{Discussão}

Ao realizar esse estudo com o objetivo de analisar os riscos biomecânicos e os sintomas osteomioarticulares de servidores que atuam em uma CME, encontrou-se participantes principalmente jovens, do sexo feminino, com predominância de 36 horas de trabaIho semanais. A amostra foi bastante heterogênea considerando os vínculos empregatícios, jornadas e locais de trabalho, além dos profissionais realizarem um rodízio, passando por todas as áreas de trabalho. A maioria dos servidores eram auxiliares de enfermagem, com ensino médio completo. A predominância do sexo feminino na enfermagem já era esperada, pois outros estudos já apresentaram essa hegemonia no Brasil e no mundo, como os estudos realizados em Palmas, TO ${ }^{14}$, no Peru e na Espanha. $\frac{15-17}{17}$

Com isso, há uma preocupação com essa prevalência do sexo feminino na área da $\mathrm{CME}$, visto que é um trabalho extremamente desgastante psicologicamente e, principalmente, fisicamente, pois envolve altos ritmos de trabalho, assim como um alto uso de força muscular. ${ }^{21}$ Este fato, vem gerando problemas posturais, como é possível observar na Figura 2, e vai de encontro com a literatura existente. $\frac{18}{18}$

Observou-se que várias atividades de trabalho na CME são realizadas em pé, com o corpo inclinado para frente (no expurgo para lavar o instrumental) ou andando. Poucas atividades são realizadas na posição sentada e há repetitividade de gestos em muitas ações (lavagem, secagem, embalagem, selagem, etc.). Além disso, o instrumental possui peso variado e muitos deles implicam em grandes esforços físicos no transporte ou levantamento realizado pelos servidores/funcionários dessa unidade.

A CME é um ambiente complexo e que possui características diferentes das demais alas hospitalares, que necessita de profissionais capacitados e preparados para atender às demandas, pois a falha desta central reflete diretamente na quantidade de infecções hospitalares nos pacientes assistidos pelo hospital. 9 O processamento de artigos hospitalares expõe os profissionais que atuam no CME a riscos biológicos, físicos e químicos. ${ }^{?}$ Esta exposição alia-se aos problemas ergonômicos, que são relacionados ao mobiliário e logística de trabalho, e aos problemas psicossociais, muitas vezes apresentados por relações de trabalho conflituosas, ritmo intenso de trabalho, alta demanda e trabalho em turnos, que podem gerar acidentes no trabalho e o adoecimento dos funcionários. ${ }^{5}$ Já os movimentos repetitivos e lesivos exercidos pelos funcionários do $\mathrm{CME}$, aliados a essa alta intensidade e demanda de trabalho, geram as disfunções musculoesqueléticas, tais como as LER/DORT.? A questão ergonômica também é preocupante, com a manutenção da postura por longos períodos e a sobrecarga física, o que corrobora com a literatura, resultando em problemas osteomusculares a longo prazo.19-21

Além disso, a posição ortostática dos trabalhadores da CME predispõe à dor lombar inespecífica ${ }^{8}$, que foi apresentada por $25 \%$ dos participantes do presente estudo. A fadiga, problema que foi apresentado por $45 \%$ dos participantes, é explicada pela utilização do corpo enquanto instrumento de trabalho, visto que a exposição a cargas fisiológicas gera diversos desgastes ao corpo. $\underline{22}$

Outro fator preocupante é que $45 \%$ dos servidores apresentarem problemas de sono e $75 \%$ apresentarem irritabilidade, que são outros fatores que trazem consequências negativas para a qualidade de vida dos trabalhadores. ${ }^{23}$ A privação do sono é algo comum nos dias atuais, em que ocorre o aumento da produtividade e de atividades diárias realizadas em função do sacrifício da quantidade de horas dormidas. Porém, o sono é responsável por diversas funções fisiológicas, incluindo a preservação e a manutenção do sistema imunológico, de acordo com Bertolazzi (2008), e a privação do sono ou o interrompimento dele por si só já é estressante. ${ }^{24}$ Ademais, quando o enfermeiro faz plantões noturnos, ocorre um desequilíbrio no sistema sono-vigília, desencadeando sensação de mal-estar, fadiga, irritabilidade e déficit de atenção.

Os acidentes de trabalho são decorrentes da exposição a diversas e simultâneas cargas e até mesmo da negligência e desatenção dos próprios trabalhadores ${ }^{25}$, o que gera a falha técnica, exposta como principal responsável dos acidentes de trabalho apresentados no presente estudo, ao lado das condições de segurança insuficientes ou inadequadas, ambas com percentual de $40 \%$. O trabalho na CME é bastante arriscado e insalubre, implicando na realização de tarefas com uso de EPIs. Entretanto, a falta de recursos e materiais nos hospitais públicos, somando-se à falta de conscientização das equipes sobre a proteção e uso de EPIs, podem favorecer os acidentes. 
Há a prevalência de acidentes de trabalho no período diurno, pois o volume de procedimentos é muito maior do que no período noturno $\frac{25}{}$, o que corrobora com os dados apresentados na Tabela 1 no presente artigo, visto que a maioria dos participantes atuam no período diurno (90\%) e que 50\% dos participantes já sofreram algum acidente de trabalho (Tabela 2). Além disso, apesar de $70 \%$ dos participantes se declararem como ativos, segundo o questionário IPAQ - versão curta, vários deles têm queixas de dores osteomusculares e o IMC está fora dos valores recomendados. Portanto, uma revisão de quais os exercícios estão sendo realizados, como está sendo feita a prescrição dos exercícios e por quem seria necessária.

As questões de saúde e de acidentes de trabalho são bastante importantes na situação estudada, e poderia ser ainda pior, caso os funcionários fossem mais antigos na instituição. No período da coleta de dados, haviam vários casos de aposentadorias da fundação e, portanto, os trabalhadores mais antigos da casa. Cabe ainda lembrar que a existência de três diferentes vínculos profissionais também pode ser geradora de conflitos, uma vez que a remuneração e outros benefícios costumam ser diferentes.

A partir da tabela 2, é possível observar que a minoria dos participantes faz uso de cigarro, ingere bebidas alcoólicas e faz uso de medicamentos. Já em relação aos acidentes de trabalho, metade da amostra já sofreu algum acidente de trabalho, sendo $80 \%$ deles com perfurocortante, mas se considerar que muitos deles se referem a problemas com o sono, isso pode prejudicar a atenção e concentração no dia seguinte. Os acidentes com perfurocortantes são os maiores responsáveis pela transmissão ocupacional de infecções sanguíneas, como o HIV, Hepatites B e C. ${ }^{25}$ Nesse estudo, os acidentes ocorrem principalmente no processo de lavagem de instrumentais, quando uma agulha ou bisturi ocasiona ferimentos percutâneos, ou ainda por contato de membrana, mucosa ou pele com sangue ou outros fluidos corpóreos potencialmente infectados.

Em relação à manifestação de sintomas recentes, as dores de cabeça, dores na coluna, ansiedade ou irritabilidade e problemas de visão foram respostas comuns a pelo menos $50 \%$ dos entrevistados, sendo que a dor de cabeça apresentou 85\% de respostas positivas. Para finalizar, a maioria deles $(80 \%)$ acredita que estes sintomas estão relacionados ao trabalho, o que leva a crer que a organização do trabalho precisa ser revista, do contrário, os profissionais podem adoecer e o absenteísmo e/ou acidentes de trabalho podem aumentar. Sendo assim, é necessário que os profissionais e as instituições hospitalares manifestem preocupação com a questão da prevenção de danos físicos e mentais a esses trabalhadores, que são tão importantes para a efetividade dos serviços hospitalares. A capacitação profissional regular pode ser uma importante estratégia para minimizar os riscos ocupacionais e biomecânicos aos trabalhadores de enfermagem.

As limitações do estudo foram a dificuldade em encontrar os trabalhadores em seus diferentes turnos de trabalho e a impossibilidade de dar continuidade à coleta de dados devido à pandemia por COVID-19.

\section{Conclusão}

Os resultados do estudo revelaram quais são os principais problemas que afetam a saúde dos trabaIhadores de uma central de material e esterilização, mais especificamente os riscos biomecânicos e os sintomas osteomioarticulares.

A prevalência de acidentes com perfurocortantes torna-se um fator preocupante, pois acontece com alta frequência, problema relacionado a condições de segurança inadequada/insuficiente ou falha técnica. Apesar de se declararem fisicamente ativos, apresentam expressivamente sintomas de dor de cabeça, dor lombar, fadiga, irritabilidade e problemas de sono. Acredita-se que essa realidade possa ser muito similar ao contexto de trabalho de outros profissionais que atuam em CME em hospitais públicos.

\section{Agradecimentos}

O presente estudo contou com auxílio financeiro advindo de bolsas de Iniciação Científica concedidas pela Universidade Federal do Paraná. 


\section{Contribuições dos autores}

Iskandar JAI participou da elaboração e delineamento do estudo; da aquisição, análise e interpretação de dados; e da redação e revisão do manuscrito. Muzeka ALP, Haus CM e Melo FARP participaram do delineamento do estudo e da aquisição de dados. Motter AA participou da elaboração e delineamento do estudo; da aquisição, análise e interpretação de dados; e da revisão do manuscrito.

\section{Conflitos de interesses}

Nenhum conflito financeiro, legal ou político envolvendo terceiros (governo, empresas e fundações privadas, etc.) foi declarado para nenhum aspecto do trabalho submetido (incluindo, mas não se limitando a subvenções e financiamentos, participação em conselho consultivo, desenho de estudo, preparação de manuscrito, análise estatística, etc.).

\section{Referências}

1. Gregório DS. Riscos Ocupacionais: uma revisão da Literatura. Id on Line Rev Psic [Internet]. 2017;11(34):401-13. Disponível em: https://idonline.emnuvens.com.br/id/article/download/697/981

2. Oliveira R, Maruyama SAT. Controle de infecção hospitalar: histórico e papel do Estado. Rev Eletr Enferm. 2008;10(3):775-83. https://doi.org/10.5216/ree.v10.46642

3. Neis MB, Gelbcke FL. Carga de trabalho em centro de material e esterilização: subsídios para dimensionar pessoal de enfermagem. Rev Eletr Enferm. 2013;15(1):15-24. https://doi. org/10.5216/ree.v15i1.17314

4. Ouriques CM, Machado ME. Enfermagem no processo de esterilização de materiais. Texto contexto - Enferm. 2013;22(3):695-703. https://doi.org/10.1590/S0104$\underline{07072013000300016}$

5. Leite ES, Silva EN, Silva EM, Santos J. Educação continuada na central de material e esterilização: significados e dificuldades enfrentadas pela enfermagem. Rev SOBECC [Internet]. 2011;16(4):31-9. Disponível em: https://revista.sobecc.org.br/ sobecc/article/download/210/pdf-a

6. Portaria no 485, de 11 de novembro de 2005 (Brasil). Aprova a Norma Regulamentadora $n^{\circ} 32$ (Segurança e Saúde no Trabalho em Estabelecimentos de Saúde). [Internet]. Brasília, DF: Ministério do Trabalho e Emprego. 2005. Disponível em: https://www.camara.leg.br/proposicoesWeb/prop_mostrarintegra;jsessionid=AODFC9671C271F924ED67242202671FC.node2?codteor=726447\&filename=LegislacaoCitada+-PL+6626/2009

7. Chiodi MB, Marziale MHP. Riscos ocupacionais para trabalhadores de Unidades Básicas de Saúde: revisão bibliográfica. Acta paul enferm. 2006;19(2):212-7. https://doi. org/10.1590/S0103-21002006000200014
8. Almeida DR, Lima GS. Conhecendo os principais sintomas da doença osteomuscular (LER-DORT) que acometem profissionais de enfermagem de uma clínica do Hospital Regional de Cáceres Doutor Antônio Fontes, Mato Grosso, Brasil. Rev Gestão Saúde [Internet]. 2014;5(4):2607-31. Disponível em: http://periodicos. unb.br/index.php/rgs/article/view/1121/973

9. Bittencourt VLL, Benetti ERR, Graube SL, Stumm EMF, Kaiser $D E$. Vivências de profissionais de enfermagem sobre riscos ambientais em um centro de material e esterilização. REME: Rev Min Enferm [Internet]. 2015;19(4):878-84. Disponível em: https:// lume.ufrgs.br/handle/10183/140330

10. Ministério da Saúde (Brasil). Organização Pan-Americana da Saúde. Doenças relacionadas ao trabalho: Manual de procedimentos para os serviços de saúde [Internet]. Brasília: Ministério da Saúde; 2001. Disponível em: http://bvsms.saude. gov.br/bvs/publicacoes/doencas_relacionadas_trabalho_manual procedimentos.pdf

11. Biblioteca Virtual em Saúde. Obesidade [Internet]. Brasília: Ministério da Saúde. 2015. Disponível em: http://bvsms.saude. gov.br/dicas-em-saude/2097-obesidade!

12. Matsudo S, Araújo T, Matsudo V, Andrade D, Andrade E, Oliveira LC, et al. Questionário internacional de atividade física (IPAQ): estudo de validade e reprodutibilidade no Brasil. Rev Bras Ativ Fis Saúde [Internet]. 2001;6(2):5-18. Disponível em: https:// rbafs.org.br/RBAFS/article/view/931

\section{Pinheiro FA, Troccoli BT, Carvalho C. Validação do} Questionário Nórdico de Sintomas Osteomusculares como medida de morbidade. Rev. Saúde Pública. 2002; 36(3):307-12. https://doi.org/10.1590/S0034-89102002000300008

14. Soares JP, Barbosa TC, Silva BKR, Zica MM, Maciel ES, Batello GVVAT, et al. Qualidade de vida, estresse, nível de atividade física e cronotipo dos auxiliares/técnicos de enfermagem em unidades de pronto atendimento em Palmas/TO. Rev CPAQV [Internet] 2017;9(1):1-9. Disponível em: http://www.cpaqv.org/revista/ CPAQV/ojs-2.3.7/index. php?journal=CPAQV\&page $=$ article\&op $=$ view\&path\%5B\%5D=180\&path\%5B\%5D=141

15. Cañadas- De la Fuente GAC, Vargas C, San Luis C, García I, Cañadas GR, De La Fuente El. Risk factors and prevalence of burnout syndrome in the nursing profession. Int J Nurs Stud. 2015;52(1):240-9. https://doi.org/10.1016/j.ijnurstu.2014.07.001

16. Condori A, Gonzales YMA, Verónica J. Calidad de vida laboral y desempeño del profesional de enfermería [monografia] [Internet]. Arequipa: Universidad Nacional de San Agustín; 2017. Disponível em: http://repositorio.unsa.edu.pe/handle/UNSA/5134

17. Rego GMV, Rolim ILTP, D'Eça Júnior A, Sardinha AHL, Lopes GSGL, Coutinho NPS. Qualidade de vida no trabalho numa central de materiais e esterilização. Rev. Bras. Enferm. 2020;73(2):e20180792. https://doi.org/10.1590/0034-7167-2018$\underline{0792}$ 
18. Shoji S, Souza NVDO, Farias SNP, Vieira MLC, Progianti JM. Proposta de melhoria das condições de trabalho em uma unidade ambulatorial: perspectiva da enfermagem. Esc Anna Nery [Internet]. 2016;20(2):303-9. Disponível em: https://www. scielo.br/scielo.php?pid=S1414-81452016000200303\&script=sci_ abstract\&tlng=pt

19. Magnano TSBS, Lisboa MTL, Griep RH, Kirchhof ALC, Camponogara S, Nonnenmacher CQ, et al. Condições de trabalho, características sociodemográficas e distúrbios musculoesqueléticos em trabalhadores de enfermagem. Acta Paul. enferm. 2010. 23(2):187-93. https://doi.org/10.1590/S0103$\underline{21002010000200006}$

20. Martins LV, Marziale MHP. Avaliação dos exercícios proprioceptivos no tratamento dos distúrbios do manguito rotador em profissionais de enfermagem: um estudo clínico controlado e randomizado. Rev Bras Fisioter. 2012;16(6):502-9. http://dx.doi.org/10.1590/S1413-35552012005000057

21. Fonseca NR, Fernandes RC. Fatores associados aos distúrbios musculoesqueléticos em trabalhadoras de enfermagem. Rev. Lat.-Am. Enferm. 2010;18(6):1076-83. http://dx.doi.org/10.1590/ S0104-11692010000600006
22. Felli VEA, Costa TF, Baptista PCP, Guimarães ALO, Anginoni BM. Exposição dos trabalhadores de enfermagem às cargas de trabalho e suas consequências. Rev Esc Enferm USP. 2015;49(esp 2):96-103. http://dx.doi.org/10.1590/S0080-623420150000800014

23. Suchecki D, D'Almeida V. Privação de sono. In: Tufik S, organizador. Medicina e Biologia do Sono. Barueri: Manole; 2008. p. 71-87.

24. Bertolazzi AN. Tradução, adaptação cultural e validação de dois instrumentos de avaliação do sono: escala de sonolência de Epworth e índice de qualidade de sono de Pittsburgh [dissertação] [Internet]. Porto Alegre: Universidade Federal do Rio Grande do Sul; 2008. Disponível em: http://hdl.handle.net/10183/14041

25. Gallas SR, Fontana RT. Biossegurança e a enfermagem nos cuidados clínicos: contribuições para a saúde do trabalhador. Rev Bras Enferm. 2010;63(5):786-92. https://doi.org/10.1590/S0034$\underline{71672010000500015}$ 